\title{
Vertical strabismus cases and their surgical outcome in Yazd, Islamic Republic of Iran
}

M.R. Besharati, ${ }^{1}$ M. Mahdavi ${ }^{1}$ and N. Ghasemi ${ }^{2}$

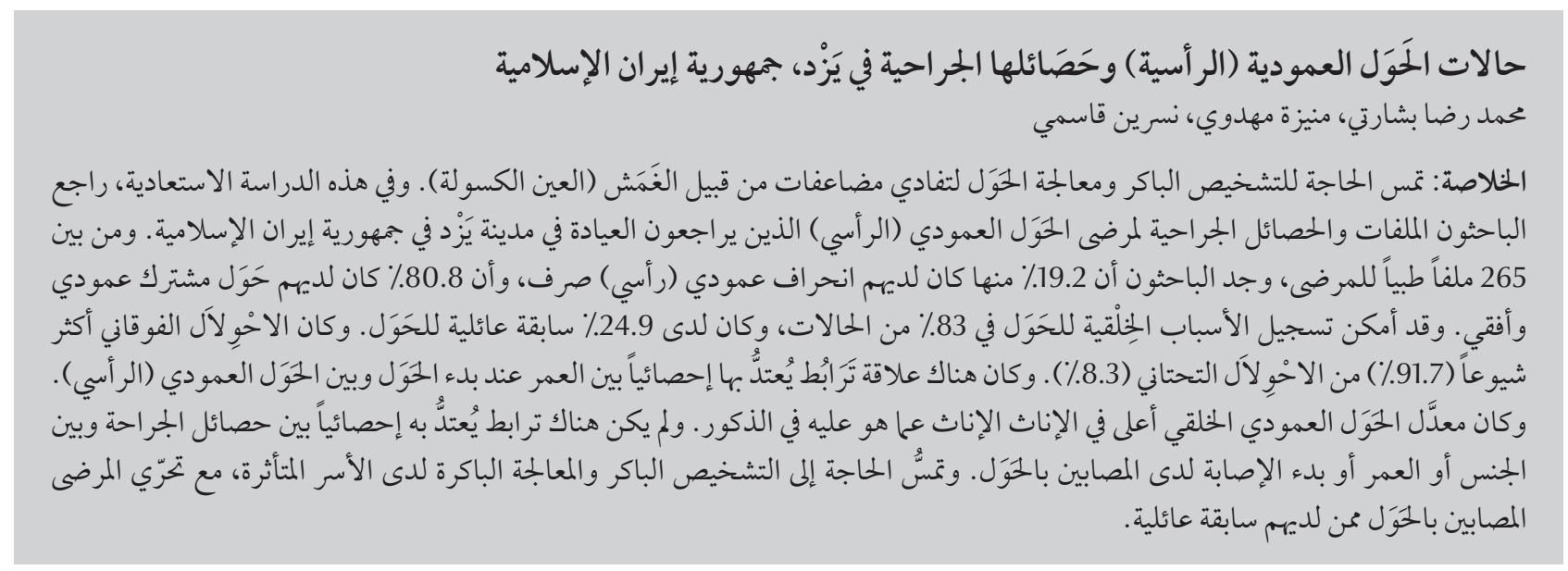

ABSTRACT Early diagnosis and management of strabismus is needed to avoid complications such as amblyopia. In this retrospective cohort study we reviewed the profile and surgical outcome of vertical strabismus patients attending a clinic in Yazd city in the Islamic Republic of Iran. From the medical files of 265 patients, 19.2\% were found to have pure vertical deviation and $80.8 \%$ had combined horizontal and vertical strabismus. Congenital causes were recorded for $83.0 \%$ of cases and $24.9 \%$ had a family history of strabismus. Hypertropia (91.7\%) was more common than hypotropia (8.3\%). There was a statistically significant relationship between age at onset and vertical strabismus. Female patients had a higher rate of congenital vertical strabismus than did male patients. There was no significant association between surgery outcomes and sex or age of onset of strabismus. Early diagnosis and management in affected families and screening of patients with strabismus family history is needed.

\section{Cas de strabisme vertical et issue des interventions chirurgicales à Yazd (République islamique d'Iran)}

RÉSUMÉ Le diagnostic et la prise en charge précoces d'un strabisme sont nécessaires pour éviter les complications telles qu'une amblyopie. Dans la présente étude de cohorte rétrospective, nous avons examiné le profil des patients atteints d'un strabisme vertical consultant en établissement de soins dans la ville de Yazd (République islamique d'Iran) et l'issue des interventions chirurgicales. L'étude des dossiers médicaux de 265 patients a mis en évidence une déviation verticale simple chez 19,2\% et un strabisme horizontal et vertical chez $80,8 \%$ d'entre eux. Des origines congénitales étaient en cause dans 83,0 \% des cas et 24,9\% avaient des antécédents familiaux de strabisme. Une hypertropie (91,7\%) était plus fréquente qu'une hypotropie (8,3\%). II existait une relation statistiquement significative entre l'âge de survenue et un strabisme vertical. Les strabismes verticaux congénitaux étaient plus fréquents chez les femmes que chez les hommes. Aucune association significative n'a été trouvée entre l'issue des interventions chirurgicales et le sexe du patient ou l'âge de survenue du strabisme. Le dépistage, le diagnostic et la prise en charge précoces sont requis dans les familles affectées et chez les patients ayant des antécédents familiaux de strabisme. 


\section{Introduction}

Although the prevalence of vertical strabismus in the population is lower than that of horizontal deviations, this type of strabismus tends to have more serious symptoms and is likely to need surgery in most cases [1]. Worldwide the prevalence of vertical strabismus had been reported to be around $1 \%-5 \%$ of the population [2-5]. Patients with vertical strabismus have more head symptoms (head tilt) than those with the horizontal type and in some cases these lead to diplopia, diminished visual acuity and palpebral fissure changes [6]. Early diagnosis and management of vertical strabismus is needed to reduce the risk of complications such as amblyopia [7].

Age of onset and early surgery are important issues in the management of vertical strabismus [8]. Studies have shown that the prevalence of strabismus in the family members of affected patients is greater than in the general population $[4,9]$. Determining a family history of strabismus can therefore help identify the population for screening [4]. Strabismus causes considerable psychosocial problems in patients and their families and dramatically decreases their quality of life [10]. The etiology of strabismus has been classified into congenital and acquired factors [5]. Smoking during pregnancy, lower age of childbearing and paediatric infection have been reported as congenital risk factors for strabismus [5].

We performed this study in Yazd, Islamic Republic of Iran, to review the profile of vertical strabismus and its surgical outcome in order to design better management strategies for vertical strabismus patients in the future.

\section{Methods}

\section{Study design and sample}

This retrospective cohort study was performed on the medical files of all vertical strabismus patients who had been newly referred for treatment to Yazd eye clinic between March 2008 and September $2010(n=265)$. Data were collected from patients who had at least 6 months postoperative follow up.

\section{Data collection}

The questionnaire had 14 items to collect data about sex, age of onset of deviation, operation performed and family history of strabismus. We classified patients based on the age of onset as $\leq 10$ years $(n=235)$ and $>10$ years $(n=30)$. Refractive errors were based on spherical equivalents (sphere $+1 / 2$ astigmatism). We classified refractive errors as normal ( $<1$ dioptre), mild (1-3 dioptres), moderate (3-6 dioptres) and severe ( $>6$ dioptres). Vertical strabismus was classified as with and without horizontal deviation (left/ right hypertropia or hypotropia were considered as vertical strabismus type). The causes of vertical strabismus were defined as one or more of: congenital, paralytic, mechanical, postoperative, traumatic, primary muscular, thyroid disease and postepilepsy. The muscles involved in paralysis (superior oblique, inferior oblique or rectus) were noted.

We recorded what kind of therapy was given including glasses, eye patch therapy, surgery or conservative therapy and follow up. Vertical strabismus surgery techniques were classified as: inferior rectus (recess or resect), superior oblique (tenotomy or tightening), superior rectus (recess or resect) or recess and resect of vertical muscles. Surgical outcomes were classified as aligned (eyes straight without any vertical deviation), undercorrection (residual deviation) or overcorrection (deviation on the reverse operation side). Postoperative complications were recorded as: undercorrection, overcorrection, dehiscence of conjunctiva, conjunctivitis, suture sensitivity, diplopia or subconjunctival haemorrhage.

\section{Statistical analysis}

Data were entered into SPSS, version 15 software and quantitative variables were presented by as mean and standard deviation (SD) and qualitative variables were presented by frequency tables (numbers and percentages). Analysis was done using the chi-squared and Fisher exact tests. $P$-values $<0.05$ were assumed to be statistically significant.

\section{Results}

\section{Background characteristics of patients}

We assessed the records of 265 patients with vertical strabismus ( 130 males and 135 females). The mean age of patients at presentation to the clinic and the mean age of onset were 15.0 (SD 11.8) years and 2.8 (SD 8.5) years respectively. Other demographic data recorded showed that $307(76.8 \%)$ were married, $181(45.3 \%)$ were from rural areas and 121 (30.3\%) were illiterate.

\section{Characteristics of vertical strabismus}

Table 1 shows the characteristics of the vertical strabismus cases. In our study $19.2 \%$ of patients had pure vertical deviation and $80.8 \%$ had combined horizontal and vertical strabismus. In the combined cases, vertical strabismus was noted with esotropia in $50.9 \%$ of patients and with exotropia in $29.8 \%$. We found no statistically significant difference in the rate of combination strabismus between the sexes $(P=0.32)$ (Table 1). However, among patients aged $\leq 10$ years at onset of strabismus $14.9 \%$ had pure vertical strabismus and $55.7 \%$ had vertical strabismus with esotropia compared with $53.3 \%$ and $13.3 \%$ respectively of patients aged $>10$ years $(P<0.001)$ (Table 2).

Most vertical strabismus types were hypertropia: bilateral (38.9\%), right (33.2\%) or left (19.6\%). Again, there was no significant association between vertical strabismus types and the sex of cases $(P=0.98)$ (Table 1$)$, but there were age differences. Bilateral hypertropia was found in $43.8 \%(103 / 235)$ of 


\begin{tabular}{|c|c|c|c|c|c|c|}
\hline \multirow[t]{2}{*}{ Variable } & \multicolumn{2}{|c|}{$\begin{array}{c}\text { Total } \\
(n=265)\end{array}$} & \multicolumn{2}{|c|}{$\begin{array}{c}\text { Males } \\
(n=130)\end{array}$} & \multicolumn{2}{|c|}{$\begin{array}{l}\text { Females } \\
(n=135)\end{array}$} \\
\hline & No. & $\%$ & No. & $\%$ & No. & $\%$ \\
\hline \multicolumn{7}{|l|}{ Deviation type } \\
\hline Pure vertical & 51 & 19.2 & 24 & 18.5 & 27 & 20.0 \\
\hline \multicolumn{7}{|l|}{ Combined horizontal and vertical } \\
\hline With esotropia & 135 & 50.9 & 62 & 47.7 & 73 & 54.1 \\
\hline With exotropia & 79 & 29.8 & 44 & 33.8 & 35 & 25.9 \\
\hline \multicolumn{7}{|l|}{ Type of vertical strabismus } \\
\hline \multicolumn{7}{|l|}{ Hypertropia } \\
\hline Bilateral & 103 & 38.9 & 51 & 39.2 & 52 & 38.5 \\
\hline Right & 88 & 33.2 & 42 & 32.3 & 46 & 34.1 \\
\hline Left & 52 & 19.6 & 25 & 19.2 & 27 & 20.0 \\
\hline \multicolumn{7}{|l|}{ Hypotropia } \\
\hline Bilateral & 2 & 0.8 & 1 & 0.8 & 1 & 0.7 \\
\hline Right & 8 & 3.0 & 5 & 3.8 & 3 & 2.2 \\
\hline Left & 12 & 4.5 & 6 & 4.6 & 6 & 4.4 \\
\hline \multicolumn{7}{|l|}{ Refractive errors } \\
\hline Hyperopia & 85 & 32.1 & 41 & 31.5 & 44 & 32.6 \\
\hline Myopia & 45 & 17.0 & 21 & 16.2 & 24 & 17.8 \\
\hline Astigmatism & 30 & 11.3 & 14 & 10.8 & 16 & 11.9 \\
\hline None & 105 & 39.6 & 54 & 51.0 & 51 & 39.6 \\
\hline Family history of vertical strabismus & 66 & 24.9 & - & - & - & - \\
\hline \multicolumn{7}{|l|}{ Cause of vertical strabismus } \\
\hline Acquired & 45 & 17.0 & 28 & 21.5 & 17 & 12.6 \\
\hline Trauma & 19 & 7.2 & 16 & 12.3 & 3 & 2.2 \\
\hline Paralytic & 14 & 5.3 & 6 & 4.6 & 8 & 5.9 \\
\hline Other & 12 & 4.5 & 6 & 4.6 & 6 & 4.4 \\
\hline Congenital & 220 & 83.0 & 102 & 78.5 & 118 & 87.4 \\
\hline Primary muscle overaction & 150 & 56.6 & 73 & 56.2 & 77 & 57.0 \\
\hline Dissociated vertical deviation & 27 & 10.2 & 12 & 9.2 & 15 & 11.1 \\
\hline Paralytic & 19 & 7.2 & 8 & 6.2 & 11 & 8.1 \\
\hline Brown syndrome & 5 & 1.9 & 2 & 1.5 & 3 & 2.2 \\
\hline Congenital fibrosis. & 2 & 0.8 & 1 & 0.8 & 1 & 0.7 \\
\hline Other & 17 & 6.4 & 6 & 4.6 & 11 & 8.1 \\
\hline \multicolumn{7}{|l|}{ Muscles involved } \\
\hline Inferior oblique overaction & 192 & 72.5 & 94 & 72.3 & 98 & 72.6 \\
\hline Superior oblique palsy & 31 & 11.7 & 15 & 11.5 & 16 & 11.9 \\
\hline Superior rectus overaction & 27 & 10.2 & 12 & 9.2 & 15 & 11.1 \\
\hline Other & 15 & 5.7 & 9 & 6.9 & 6 & 4.4 \\
\hline
\end{tabular}

patients with age of onset $\leq 10$ years but in none $(0 / 30)$ of those aged $>10$ years.

The inferior oblique $(72.5 \%)$ and superior oblique (11.7\%) were the most common muscles involved (Table 1).

Refractive errors were found in one or both eyes of $60.4 \%$ of patients.
Hyperopia and myopia were the most common refractive errors $(32.1 \%$ and $17.0 \%$ respectively) (Table 1 ).

\section{Causes of vertical strabismus}

Examination of referral patterns showed that more than half of patients had vertical strabismus at the time of birth. The most common causes of vertical strabismus were congenital in 220 cases (83.0\%). Female patients had a significantly higher rate of congenital vertical strabismus than male patients $(87.4 \%$ versus $78.5 \%)(P=0.04)($ Table 1$)$. The 


\begin{tabular}{|c|c|c|c|c|}
\hline \multirow[t]{3}{*}{ Deviation type } & \multicolumn{4}{|c|}{ Age at onset (years) } \\
\hline & \multicolumn{2}{|c|}{$\leq 10(n=235)$} & \multicolumn{2}{|c|}{$>10(n=30)$} \\
\hline & No. & $\%$ & No. & $\%$ \\
\hline Pure vertical & 35 & 14.9 & 16 & 53.3 \\
\hline Combined with exotropia & 69 & 29.4 & 10 & 33.3 \\
\hline Combined with esotropia & 131 & 55.7 & 4 & 13.3 \\
\hline
\end{tabular}

congenital forms were mainly due to primary muscle overaction in $56.6 \%$ of patients, followed by dissociated vertical deviation (10.2\%) and paralytic causes $(7.2 \%)$. In patients with age of onset $\leq$ 10 years old, primary hypertropia (177 cases) and paralytic causes (25 cases) were the most common congenital causes. Among cases with primary overaction, 150 were congenital and 16 were acquired overaction.

The remaining 45 cases $(17.0 \%)$ had acquired causes of vertical strabismus. Trauma was the most common acquired cause $(7.2 \%)$ and the rate in male patients (12.3\%) was significantly higher than in females (2.2\%) (Table 1) $(P<0.001)$. Trauma was the cause in $14(46.7 \%)$ of patients aged $>10$ years at onset of strabismus compared with only $5(2.1 \%)$ of those aged $\leq 10$ years.

A quarter of the patients (24.9\%) had a positive family history of vertical strabismus.

\section{Surgical treatment}

A total of 101 cases (38.1\%) were treated surgically (Table 3 ). The mean length of hospital stay was 1.5 (1.1) days. The most common surgical procedures were inferior oblique recess in 77 cases (76.2\%), superior rectus recess in 23 (22.8\%) and inferior rectus recess in 12 cases (11.9\%) (surgery was done on more than 1 muscle). The records of the operation showed that $80(79.2 \%)$ had 1 stage, $18(17.8 \%)$ had 2 stages and $3(3.0 \%)$ had 3 or more stages of surgery. During 6 months follow-up, the outcome was aligned for $53.5 \%$ of patients, undercorrected for $29.7 \%$ and overcorrected for $5.9 \%$ (no follow-up data available for $10.9 \%$ of cases). There was no significant difference between the sexes in the outcome of surgery (Table 3 ). There was also no difference according to age of onset of strabismus; 55/90 (61.1\%) of those aged $\leq 10$ years had successful alignment versus $7 / 10(70.0 \%)$ of those aged $>10$ years $(P=0.614)$.
One-third of these patients (33.7\%) developed complications of surgery, most commonly subconjunctival haemorrhage in 15 cases (14.9\%) and conjunctival infection in $6(6.0 \%)$. There were 5 cases (5.0\%) with postoperative diplopia, which was eradicated in all except 1 case which was managed with prisms. No significant relationship was seen between the mean age of onset of vertical strabismus and presence of surgical complications, or between type of vertical strabismus and surgical complications $(P>0.05)$ (data not shown).

\section{Discussion}

This study show no significant differences in the numbers of males and females presenting to this clinic with vertical strabismus, and this agrees with the studies of Chang et al. [11] and Bagheri et al. [12,13]. Others, however,

\begin{tabular}{|c|c|c|c|c|c|c|}
\hline \multirow[t]{2}{*}{ Variable } & \multicolumn{2}{|c|}{ Total } & \multicolumn{2}{|c|}{ Males } & \multicolumn{2}{|c|}{ Females } \\
\hline & No. & $\%$ & No. & $\%$ & No. & $\%$ \\
\hline Surgical treatment & & $(n=265)$ & & $(n=130)$ & & $(n=135)$ \\
\hline Yes & 101 & 38.1 & 46 & 35.4 & 55 & 40.7 \\
\hline No & 164 & 61.9 & 84 & 64.6 & 80 & 59.3 \\
\hline Outcome of surgery & & $(n=101)$ & & $(n=46)$ & & $(n=55)$ \\
\hline Aligned & 54 & 53.5 & 23 & 50.0 & 31 & 56.4 \\
\hline Undercorrected & 30 & 29.7 & 16 & 34.8 & 14 & 25.5 \\
\hline Overcorrected & 6 & 5.9 & 2 & 4.3 & 4 & 7.3 \\
\hline No follow-up & 11 & 10.9 & 5 & 10.9 & 6 & 10.9 \\
\hline Complications of surgery & & $(n=101)$ & & $(n=46)$ & & $(n=55)$ \\
\hline Yes & 34 & 33.7 & 16 & 34.8 & 18 & 32.7 \\
\hline No & 67 & 66.3 & 30 & 65.2 & 37 & 67.3 \\
\hline
\end{tabular}


have reported that the prevalence of vertical strabismus was higher in males than females [14,15]. Najafi's study in Islamic Republic of Iran found that the prevalence of hypertropia was similar between the sexes but hypotropia due to traumatic events was higher in males than females [15]. The small sample sizes and differences in epidemiological characteristics might explain the differences between study fndings.

The mean age of patients presenting was 15.0 (SD 11.8) years and more than half of them were affected from birth. It confirms that congenital causes of vertical strabismus were more common in this study than the acquired forms. Abrishami and Bagheri's study on 73 patients with superior oblique palsy reported that the mean age of cases was 19.7 (SD 11.7) years [16], while Simons and Saunders reported a mean age of superior oblique palsy of more than 30 years and confirmed that acquired factors were more common in the pathogenesis of superior oblique palsy [17].

In our study $24.9 \%$ of cases had a family history of strabismus, similar to Mvogo and Ellong, who reported $28.7 \%$ of cases had a positive family history and that in most of them the deviation type was similar to that of other family members [18]. Wilmer and Backus reported that genetics had an important role in etiology of strabismus [19]. Although positive family history in our cases did not confirm a genetic role in the pathogenesis of vertical strabismus, it might be an interesting topic for future studies.

Refractive errors were found in $60.4 \%$ of patients and hyperopia was the most common type. Bagheri et al. [12] and Najafi [15] had similar findings as our study but Abrishami and Bagheri showed a higher prevalence of refractive errors and myopia [16]. This high rate of refractive errors may confirm that refractive error is a risk factor for strabismus.
Vertical strabismus is frequently associated with horizontal strabismus and our results showed that in a majority of cases vertical strabismus was combined with horizontal deviation ( $80.8 \%$ of cases). Esotropia was the most common combination type. Chang and Yang reported the same results in a study of patients with hypertropia due to inferior oblique overaction [20]. In contrast, Abrishami and Bagheri reported that exotropia was more common with vertical strabismus than was esotropia [16]. In our study presumably due to congenital factors, esotropia was more common in cases aged $\leq 10$ years and exotropia in cases aged $>10$ years.

In our study hypertropia (91.7\%) was more common than hypotropia (8.3\%). In Bagheri and Eshaghi's study on patients with superior oblique palsy, monocular was significantly more common than bilateral involvement [21]. The higher rate of hypertropia in our study may be due to the higher prevalence of inferior oblique overaction $(72.5 \%)$ than superior oblique palsy (11.7\%). In our study bilateral involvement was more common in cases $\leq 10$ years old and unilateral involvement in cases $>10$ years old, presumably due to a higher incidence of acquired factors in this age group.

In our study congenital factors were more prevalent than acquired ones (83.0\% versus $17.0 \%$ ), and this agrees with Megha and Tollefson's [22] and Kaczmarek's [23] studies. In contrast, Simons and Saunders [17] and Parks and Mitchell [24] reported a higher prevalence of acquired factors, especially trauma. In general, early diagnosis is made in most cases of congenital vertical strabismus when it is accompanied by the horizontal type.

The prevalence of dissociated vertical deviation and Brown syndrome were $10.2 \%$ and $1.9 \%$ respectively in our study. The prevalence of dissociated vertical deviation has been reported in other studies as varying from $17.0 \%$
[20] to $7.1 \%$ and $5.8 \%$ [12] respectively. Brown syndrome has been reported as $1.8 \%[22]$.

In our study, $61.9 \%$ of cases were managed without any surgery. This may be due to the presence of cases of clinically insignificant, small-angle deviation or patient factors such as fear of surgery or not attending for follow-up. The most frequent surgery types were inferior oblique recess and superior rectus recess. Most patients (79.2\%) had 1-stage surgery while $17.8 \%$ had 2-stage surgery.

With 6 months postoperative follow-up, $61.1 \%$ of our cases showed excellent results without any vertical deviation. Morris's study showed 52\% of patients had no deviation 9 months after operation on the vertical rectus [25]. In Moon and Lee's study on 22 patients with superior oblique palsy who had inferior oblique recess the recess operation and remission rate during 12 months follow up was $91 \%$ [26]. In Hatz et al.'s [27] and Maruo and Kubota's studies [28], the rate of inferior oblique recess surgery was greater and the vertical deviation was more severe, and due to residual deviation cases needed a second operation on the vertical rectus muscle. Inferior oblique recess was the most common operation type and the outcome was good in $82.6 \%$ of Oguz et al.'s cases [29]. Better outcome rates in Oguz et al.'s study than in our study may be due to differences in the definition of residual deviation of $\leq 4$ primary deviations. According to these studies, inferior oblique recess was the most common operation for vertical deviation and most patients recovered with the first stage of surgery but in cases of large deviation second-stage surgery was necessary. More than one operation technique and continuous follow up and management of patients is sometimes necessary for achieving better outcomes.

Subconjunctival haemorrhage in $14.9 \%$ and conjunctivitis in $6.0 \%$ were 
the most common postoperative complications in our cases. Severe infection was uncommon in postoperative follow up. Although cellulitis is a severe postoperative complication it has rarely been reported in previous studies [30]. Conjunctival cyst with subconjunctival noninflammatory mass might be seen from a few days until a few weeks after surgery [30]. We did not have any cases of cellulitis or conjunctival cyst in the current study. Diplopia was reported to be a common complication in elderly patients which generally disappeared a few hours to a few months after fusion but remained fixed in some cases [30]. In our study we had 5 cases with postoperative diplopia, and this was eradicated in all except 1 case, which was managed with prisms.

\section{Conclusions}

Our study showed that the most common causes of vertical strabismus were congenital and many patients had a family history of vertical strabismus. Although some congenital causes are not preventable, early diagnosis and management in affected families and screening of patients with a family history of strabismus may decrease the risk of complications.

\section{References}

1. Tollefson MM et al. Incidence and types of childhood hyy pertropia: a population-based study. Ophthalmology, 2006, 113:1142-1145.

2. Donnelly UM, Stewart NM, Hollinger M. Prevalence and outcomes of childhood visual disorders. Ophthalmic Epidemiology, 2005, 12:243-250.

3. Auzemery A, Andriamanamihaja R, Boisier P. Enquête sur la prévalence et les causes des affections oculaires chez les enfants des écoles primaires d'Antananarivo [A survey of the prevalence and causes of eye disorders in primary school children in Antananarivo]. Santé, 1995, 5:163-166.

4. Abrahamsson M, Magnusson G, Sjostrand J. Inheritance of strabismus and the gain of using heredity to determine populations at risk of developing strabismus. Acta Ophthalmologica Scandinavica, 1999, 77:653-657.

5. Arora A et al. Decreasing strabismus surgery. British Journal of Ophthalmology, 2005, 89:409-412.

6. Superior oblique palsy and superior oblique myokymia. In: Rosenbaum AL, ed. Clinical strabismus management. Philadelphia, WB Saunders, 1999:219-227.

7. Matsuo $\mathrm{T}$ et al. Detection of strabismus and amblyopia in 1.5- and 3-year-old children by a preschool vision-screening program in Japan. Acta Medica Okayama, 2007, 61:9-16.

8. Hatt $S$, Gnanaraj L. Interventions for intermittent exotropia. Cochrane Database of Systematic Reviews, 2006, 3:CD003737.

9. Ziakas NG et al. A study of heredity as a risk factor in strabismus. Eye, 2002, 16:519-521.

10. Lilakova D, Hejcmanova D, Novakova D. [Effect of strabismus on the quality of life in adults]. Ceska a Slovenska Oftalmologie, 2003, 59:184-187 [in Czech].

11. Chang $\mathrm{YH}$ et al. Anterior transposition of inferior oblique muscle for treatment of unilateral superior oblique muscle palsy with inferior oblique muscle overaction. Yonsei Medical Journal, 2004, 45:609-614.

12. Bagheri A et al. [Position and circumference of the inferior oblique muscle in patients with inferior oblique overaction]. Bina Journal of Ophthalmology, 2008, 13:217-221 [in Farsi].

13. Bagheri A, Sahebghalam R, Abrishami M. [Double elevator palsy: a 10-year review of operated patients]. Bina Journal of Ophthalmology, 2006, 12:81-88 [in Farsi].

14. Von Noorden G, Campos E, eds. Binocular vision and ocular motility. New York, Mosby, 2002.

15. Najafi A. Prevalence and management outcome of strabismus in patients of eye surgery center of Shahid Labbafinejad Hospital. Medical Journal of Azad University, 2007, 17:33.
16. Abrishami M, Bagheri A. [Causes and outcomes of treatment for superior oblique palsy during a decade at Labbafinejad medical center.] Bina Journal of Ophthalmology., 2009, 14:354-360 [in Farsi].

17. Simons B, Saunders T. Outcome of surgical management of superior oblique palsy: a study of 123 cases. Binocular Vision and Strabismus Quarterly, 1998, 13:273-282.

18. Mvogo C, Ellong A. Hereditary factors in strabismus. Sante, 2001, 11:237-239.

19. Wilmer J, Backus B. Genetic and environmental contributions to strabismus and phoria: evidence from twins. Vision Research, 2009, 49:2485-2493.

20. Chang BL, Yang SW. Inferior oblique overaction. Korean Journal of Ophthalmology, 1988, 2:77-81.

21. Bagheri A, Eshaghi M. [Botulinum toxin injection into inferior oblique muscle for treatment of acquired superior oblique palsy]. Bina Journal of Ophthalmology, 2005, 11:107-115 [in Farsi].

22. Megha M, Tollefson. Incidence and types of childhood hypertropia. Ophthalmology. 2006, 113:1142-1145.

23. Kaczmarek B. [Outcomes of surgical management in adults with unilateral superior oblique muscle palsy]. Klinika Oczna, 2006, 108:60-65 [in Polish].

24. Parks M, Mitchell P. Cranial nerve palsies. In: Tasman W, Jaeger E, eds. Duane's clinical ophthalmology. Philadelphia, Lippincott-Raven, 1996:1-17.

25. Morris RJ. Inferior rectus recession an effective procedure? British Journal of Ophthalmology, 1997, 81:1031-1036.

26. Moon K, Lee SY. The effect of graded recession and anteriorization on unilateral superior oblique palsy. Korean Journal of Ophthalmology, 2006, 20:188-191.

27. Hatz K, Brodsky M, Killer H. When is isolated inferior oblique muscle surgery an appropriate treatment for superior oblique palsy? European Journal of Ophthalmology, 2006, 16:10-16.

28. Maruo T, Kubota N. Outcome of surgery for congenital fibrosis of the inferior rectus muscle. Binocular Vision and Strabismus Quarterly, 2001, 16:105-110.

29. Oguz $\vee$ et al. Les résultats de la chirurgie de l'oblique inférieur dans la paralysie de l'oblique supérieur [Results of inferior oblique muscle surgery in superior oblique paralysis]. Journal Francais d'Ophtalmologie, 2003, 26:831-833.

30. Besharati M, Lotfi M, Nourani F. Outcomes and complications of strabismus surgery in Yazd. International Journal of Ophthalmology, 2008, 8:1104-1107. 